\title{
La réception de Marie Dauguet dans la presse de la Belle Époque
}

\author{
Carmen RAMírez Gómez \\ Universidad de Sevilla \\ cramirez@us.es \\ https://orcid.org/oooo-0002-5742-7959
}

\section{Resumen}

Este artículo estudia la recepción de la poetisa Marie Dauguet en la prensa francófona de la "Belle époque". Para proceder a la investigación, hemos establecido un corpus de prensa del cual hemos consignado información bibliográfica, poemas, artículos, reseñas y fotografías. De esta red discursiva, hemos seleccionado la información biográfica y las reseñas críticas de las obras de Dauguet publicadas entre 1900 y 1914. A partir del análisis de estos datos, nuestro estudio plantea une nueva perspectiva para abordar la biografía de esta letrada, así como la presencia y el alcance de esta autora en la literatura francesa del siglo XX, y en las letras femeninas en particular, estableciendo en filigrana un discurso sobre la cuestión de las mujeres y la literatura.

Palabras clave: recepción, Dauguet, prensa, mujeres, literatura.

\section{Résumé}

Cet article est consacré à la réception de la poétesse Marie Dauguet dans la presse francophone de la Belle Époque. Pour mener à terme cette étude, nous avons établi un corpus de périodiques dont nous avons extrait l'information bibliographique, les poèmes, les articles, les comptes rendus, les photographies. De ce maillage discursif, nous avons retenu l'information biographique et les comptes rendus des ouvres de Dauguet publiées entre 1900 et 1914. À partir de l'analyse de ces données, notre étude propose une remise en perspective de la biographie de la dame de lettres, mais aussi de la présence et la portée de la poétesse, dans la littérature française du $\mathrm{XX}^{\mathrm{e}}$ siècle et dans les lettres féminines en particulier, interrogeant en parallèle la question des femmes et de la littérature.

Mots clé : réception, Dauguet, presse, femmes, littérature.

\section{Abstract}

This article studies the reception of the poet Marie Dauguet in the Frenchspeaking press of the "Belle Époque". To proceed with this research, we have established a corpus based on press articles from which bibliographic information,

${ }^{*}$ Artículo recibido el 25/09/2021, aceptado el 5/11/2021. 
poems, articles, reviews and photographs have been gathered. This discursive network has allowed to select the biographical information and critical reviews related to Dauguet's works published between 1900 and 1914. The study offers a new perspective which stems from the analysis of these data and sheds new light on the biography of this woman of letters. It furthermore determines the author's presence and impact in 2oth Century French Literature, and in female letters in particular. A parallel discourse on the question of women and literature is also established.

Keywords: reception, Dauguet, press, women, literature.

\section{Introduction}

Née sous les fastes du Second Empire, en 1860, Marie Dauguet mourra en 1942, en pleine guerre mondiale. En 1960, le centenaire de sa naissance devient l'occasion de dénoncer le silence que la critique semble jusqu'alors lui avoir réservé. Jeanine Moulin (1960) consacre à cette «Colette de la poésie » un article dans les Annales de l'université, repris dans son anthologie féminine de 1963. Notre enquête souhaite nuancer ce point de vue, et montrer qu'il a existé un discours critique sur Marie Dauguet, qui desserre la chaîne du silence et du mépris, et perce les murs de l'ignorance et de l'indifférence.

Notre corpus a été constitué selon trois critères : la disponibilité et l'accessibilité des fonds périodiques (Bellanger et al., 1972 ; Eck \& Blandin, 2010 ; Feyel, 2010 ; Palmer, 2016), le choix d'adopter des limites chronologiques amples (1900-1960) pour cerner la spécificité du cadre de la Belle Époque (1900-1914) et un dépistage systématique des occurrences. La consultation de la presse périodique permet d'établir trois phases de la réception. La période 1900-1914 correspond à la phase la plus intense de la réception de Marie Dauguet. Après la parenthèse de la Première guerre mondiale, une deuxième étape moins dense se déroule de 1920 à 1930, et à partir de 1931 jusqu'à 1960 (et au-delà) les références sont plus discontinues.

\section{Marie Dauguet, à la croisée des $\mathrm{XIX}^{\mathrm{e}}$ et $\mathrm{XX}^{\mathrm{e}}$ siècles}

Julie Marie Dauguet naquit et passa la plus grande partie de sa vie en Franche-Comté. Son père, Louis Ferdinand Aubert, dirigera les forges de la Chaudeau jusqu'à l'arrivée de son beau-fils, le futur époux de Marie, Henri Marie Dauguet (1881-1924), qu'elle épouse en 1881 et avec qui elle a une fille, Suzanne Pauline (1882-1957). À la mort de son époux, en 1924, Marie Dauguet vivra à Enghien et mourra dans une villa de retraités à Villed'Avray (Île-de-France).

C'est dans ce pays de forêts, de sources et de minéraux qu'elle écrit sa vie durant. Elle s'y ressource pour poétiser une nature et des paysages qu'elle saura convertir en héritage littéraire dans le sillage des Anciens (Anacréon, Horace, Lucrèce, Catulle, Tibulle, Virgile, Pindare, Hésiode, Homère) et des Modernes (Ronsard, Baudelaire, Anna de Noailles, Jammes, entre 
autres). Il est impossible d'envisager la vie, l'œuvre et la réception de cette poétesse si ce n'est dans l'appréhension de ce cadre géographique vosgien. Pourtant, elle ne se confinera pas à sa province : on la découvrira voyageuse, par ses séjours à Paris, par l'Italie qu'elle visite (Dauguet, 1907), par « l'espace [qui] s'amplifie » jusqu'à « l'infini » (Dauguet, 1909 : 71). Mais elle revient toujours à ses terres. Elle sera d'ailleurs considérée une muse du terroir (Sadoul, 1909: 782 ; Van Bever, 1909: II, 160- 164) et occupera une place de choix dans le cadastre littéraire de Dorgelès (1912: 367), émulant l'ancien Parnasse ${ }^{1}$. C'est dans ce contexte territorial, local et familial, notamment du Beuchot, que s'inscrivent les deux premières occurrences significatives de Marie Dauguet dans la presse du début du siècle : un fait divers et une affaire politique (Parville, 1901: 2 ; Charles, 1901:1).

De ces premières mentions dans la presse émerge l'esquisse d'une femme lettrée, mélomane, aimante de la nature, grande lectrice, à la vie aimable et attachée à ses racines, à son histoire. La suite des références ne démentira pas le portrait initial de cette franc-comtoise consacrée à ses plaines, à la lecture et à l'écriture. Elle sera aussi une femme rattachée à la République des lettres de son temps et à Paris, comme le démontrent ses publications et leur réception dans la presse notamment, signée par des lettrés importants de l'époque.

L'ensemble des comptes rendus critiques consacrés aux œuvres de Dauguet structurent un maillage d'informations biobibliographiques, littéraires, culturelles et idéologiques à partir des jugements des œuvres de Dauguet publiées entre 1902 et 1913. Les premières références à Marie Dauguet dans la presse datent de 1901. Un an plus tard, le Mercure de France ${ }^{2}$ publie son poème intitulé « À la primevère » (Dauguet, 1902a : 410-412), appartenant au premier recueil poétique, À travers le voile (Dauguet, 1902b), composé entre novembre 1899 et novembre 1901, et paru le 13 juin 1902 sous les presses de Vanier, l'éditeur des décadents et des symbolistes. Ce premier volume vaudra à Marie Dauguet d'être présentée au monde comme " un nouveau poète » (Cabs, 1902 : [2]) et d'être déclarée un " vrai poète » $(\mathrm{Fa}-$ guet, 1902 : 528-534), aux nombreux défauts à corriger.

\section{Le premier élan poétique (1902-1907)}

\section{1. À travers le voile (1902)}

En juin 1902, deux chroniqueurs anonymes sont les premiers à se prononcer sur À travers le voile, qui vient de paraître. Cette dame des forêts vosgiennes résume selon eux une dichotomie opposant la sauvagerie de la

\footnotetext{
${ }^{1}$ Une décade plus tard, on ne manquera pas de suggérer une révision de cette carte dressée en 1912 (Les Méridiens, 1925 :2). Le Goffic (1925:1-16) écrivain régionaliste (Thiesse, 1983 : 37), la reprendra, pour illustrer ses propos sur la littérature régionaliste.

2 Elle est d'ailleurs collaboratrice de cette revue et de bien d'autres : Artiste, Durendal, Franche-Comté Monts-Jura, Gil Blas, L'Ermitage, La Fronde, La Grande Revue, La Lorraine, La Plume, La Revue Hebdomadaire, La Revue Idéaliste, La Revue Latine, Le Beffroi, Le Figaro, Le Penseur, Le Thyrse, Les Annales, Les Lettres, Minerva, Poesia, Vox.
} 
paysanne, la subtilité de la femme du monde et la sagesse et l'érudition de la dame qui dédie ses poèmes à Faguet et à Brunetière (Anon., 1902a : 3). Le recueil leur parait une composition « charmante », à « lecture aimable » (Pip, $1902:$ 423) que favorise un paysage verdoyant et plaisant. Ces chroniques oublient souvent la beauté de ses textes, à la faveur de ses bontés maraîchères. «A. de B. » (1902 : [4]) souligne son amour de la nature et son univers sensoriel. La peinture, la musique et les sensations, en particulier les parfums, constituent des éléments essentiels de sa perception de la nature et de sa conception poétique, témoignant en partie de sa " curiosité universelle » (Dauguet, [1908b] : 59). Dauguet n'est pas étrangère à la théorie des correspondances de Baudelaire, et utilise le terme de « synesthétique vibrance de la vie » pour définir son idéal poétique basé sur " [les] lignes, [les] formes, [les] couleurs, [les] parfums [...] 》 (Dauguet, [1908b] : 59). Cabs (1902 : [2]) réinsère À travers le voile dans les mouvements littéraires de l'époque, libre des emprises du lyrisme boulevardier et de l'académisme.

La composition et la langue du recueil sont rarement abordées. L'helléniste et critique Pierre Quillard (1902 : 738-739) apporte une série d'éléments intéressants sous cet angle et nuance le portrait de la poétesse : elle écrit avec des mots de patois, pour dire des paysages champêtres proches des territoires mythiques des Ménales et Érymanthe. Cette dualité dans le choix de la langue correspond, selon lui, au savoir de cette poétesse qui associe l'érudition de ses lectures d'œuvres classiques et contemporaines à des connaissances des modernes, symbolistes, décadents et même futuristes. Faguet s'oppose à cette idée (Faguet, $1902: 528$ ), n'admettant qu'un certain rapprochement avec Ronsard, Chénier et Lamartine, une langue sans artifice, et une observation précise du monde et de la nature, exprimée par les sensations. Or les strophes choisies par Quillard ( "Ma Flûte rauque », « J'ai trop cueilli » (Faguet, 1902 : 738-739) illustrent sa maitrise des analogies et des correspondances. Selon Quillard, Dauguet s'inscrit dans la tradition des poètes du Grand Siècle, comme Tristan et Théophile de Viau. Un mois plus tard, Édouard Pesch (1902 : 3), pour sa part, reviendra sur l'élégance de la langue, la richesse des idées et la savante composition des poèmes de ce recueil. Mais les réserves ne manquent pas envers la poétesse et la femme. Émile Faguet et René Faralicq incarnent deux versions de cette réticence. Faguet (1902 : 528-534) salue la venue d'un « vrai poète " sans croire encore à sa grandeur. S'il loue la sensibilité, la souplesse, la musicalité et la séduction de ses vers, Faguet critique leur manque d'imagination et les maladresses du style et de la prosodie : contrairement à bon nombre de critiques, cette promeneuse est marquée par « une éducation littéraire inconsistante » (Faguet, 1902: 528)3. Il propose une comparaison au goût douteux : Marie Dauguet est « une belle plante qui saurait chanter » (Faguet,

3 C'est ce qu'il développe dans ses théories sur le féminisme : les femmes doivent et savent écrire des romans, mais le travail des vers « irrite l'impatience et l'impétuosité féminines (Faguet, $1910: 56$ ) tout en reconnaissant que « Le romantisme a libéré la muse féminine » (Faguet, $1910: 56$ ). 
1902 : 528). Malgré ce jugement, il salue la naissance d'un poète charmé par la nature et envoûté par « l'âme des petites choses » (Faguet, $1902: 532$ ).

René Faralicq (1902 : 342-345) rejoint Faguet dans ce clivage entre la reconnaissance de la poétesse et le dénombrement de ses défauts. Selon Faralicq, les défauts de la poésie harmonieuse et délicate de Dauguet puisent leur source dans l'emploi du vers libre, les maladresses prosodiques et autres bizarreries modernes (Faralicq, 1902 : 342-345). Il établit aussi un classement de poétesses, à l'avantage d'Anna de Noailles, et au détriment des « poètes mâles » (Farlicq, 1902 : 345). Dauguet sera constamment confrontée à ses consœurs et à ses confrères. Si Farlicq évoque une certaine supériorité des poétesses, un chroniqueur anonyme définit son recueil comme un texte «pensé par un homme, senti par une femme » (Anon., 1902a : 3). La femme restait liée au domaine des affects et des émotions, face à la capacité raisonnable de l'homme4.

Aux antipodes de telles considérations, d'Harlor (Jeanne Fernande Perrot), femme de lettres, féministe, rédactrice de La Fronde, souligne la maîtrise des femmes poètes, "vraiment femmes ", sachant écrire des vers sans perdre ni leur humanité ni leur essence féminine (Harlor, 1902 : 2). Selon Harlor, Marie Dauguet est une femme poète dont la sensibilité et l'art servent l'expression sensuelle de la nature, sans artifice et sans vulgarité, à l'opposé de la poésie populaire. Contrairement à Faguet, elle ne doute ni de ses lectures ni de sa connaissance de la poésie. L'analyse de son volume $\grave{A}$ travers le voile met en lumière l'autobiographisme, la fantaisie, l'observation et l'émotion de la poétesse devant « les choses » de la nature, vues par la femme et décrites par l'écrivaine.

Dès ce premier recueil Marie Dauguet se montre en tant que femme érudite et lectrice férue, maîtrisant les Anciens et les Modernes. C'est une poétesse qui travaille ses images et ses visions dans la langue commune, sans oublier les mots du patois. Marie Dauguet utilise, défend et théorise aussi le vers libre. Héritage du symbolisme, conquête de la poésie moderne, le vers libre ouvre un débat que se prolonge encore à la Belle Époque (Merello, 2010 : 13-23). Selon Marie Dauguet (1906 : 228), il exprime le mieux les émotions, « l'expression immédiate de la nature et de l'instinct ». Le vers classique, " mesuré, cadencé », représente par son artificialité et sa fine élaboration une marque suprême du "purement humain » (Dauguet, 1906 : 228). La poétesse associe le vers-librisme à la synesthésie (Dauguet, 1909 : 39-40). Elle participera à l'enquête de Marinetti en 1909, mais elle ne sera pas citée dans la première enquête sur le vers libre (Le Cardonnel et Vellay, 1905).

4 Cette conception genrée des émotions assimilant la masculine /féminin au binôme raison/émotion se rattache à l'ancienne tradition de la théorie des tempéraments assimilant "les humeurs chaudes aux hommes (colère, fureur, hardiesse, haine) et les humeurs froides aux femmes (modestie, douceur, crainte, pudeur, compassion, langueur) » (Boquet et Lette, $2018: 1-2)$. 
Aussi à la simplicité de ses compositions faut-il ajouter cette recherche poétique dans des matériaux et des sources diversifiés et polymorphes que les titres de ce premier recueil ne démentent pas : "Sur la rive », " Brumaire », " Au bord de l'ombre », "Jadis », " Cendres et pourpres », " Chansons », « Musique », « La forge », " La chanson d'Ophélie » ou le « Sonnet des sérénités » (Dauguet, 1902).

En 1903, les comptes rendus consacrés au recueil $A$ travers le voile se poursuivent replaçant Marie Dauguet dans le mouvement des poétesses du temps et développant en filigrane un discours sur les femmes poètes. C'est le cas de Stuart Merrill (1903 : 29-44) et d'Alcanter de Brahm (1903 : 1). Dans sa rubrique intitulée la "Poésie nouvelle » consacrées aux vers libres, trois femmes poètes trouvent leur place : la comtesse de Noailles, Delarue-Mardrus et Dauguet. Ce sont des habituées des chroniques littéraires. Comme bien d'autres critiques, Alcanter de Brahm divise la littérature féminine en deux groupes : d'un côté, la haute poésie féminine, représentée par les « Poétesses mondaines » (Riotor, 1903 : [1]), et de l'autre côté, la modeste poésie bucolique de Dauguet et de son $A$ travers le voile. Stuart Merrill est indulgent dans l'éloge d'une poésie simple et vraie, aux échos de Baudelaire, Régnier, et Verlaine. Pour lui Marie Dauguet est la « modeste Cendrillon de la trilogie sororale » (Brahm, 1903 : [1]). La formule est sans appel : Dauguet est à nouveau présentée au monde en arrière-plan. À l'instar de Harlor et de Faralicq, Merrill affirme l'égalité des hommes et des femmes dans l'écriture ; en revanche son propos n'est que rhétorique et condescendance envers les femmes auteurs réussissant à devenir " artistes et rester femmes » (Merrill, 1903 : 29). La nature féminine ne semble être qu'un attribut éphémère, apparemment incompatible avec certaines activités de l'esprit réservées aux autres. La formule est lourde mais elle n'est pas anodine, représentative d'opinions communes, et rappelant les propos basbleuistes parus dans cette même revue, quelques décennies plus tôt 5 . Merrill poursuit sa leçon de critique littéraire et distingue une pléiade de poétesses, notamment Lucie Delarue-Mardrus, la Comtesse de Noailles, Jeanne Perdriel-Vaissière, Sybil O'Santry, Renée Vivien, et Marie Dauguet, des anciennes muses de keepsake (Colet, Tastu ou Ségalas), ou d'un romantisme suranné et privé de vérité humaine. Selon Merrill (1903 : 29), le premier recueil de Dauguet est le signe de la naissance d'un poète encore incomplet et qui « fait parfois de la littérature » (Merrill, 1903 : 33). À l'instar de ses prédécesseurs, Merrill (1903 : 30) applique à cette poétesse la dualité des valeurs du terroir (rustique, populaire, provincial, ancestral) et celles des émotions inspirées par la nature ( "la sincérité, la pureté, la simplicité, l’honnêteté » (Merrill, 1903: 33). Outre ces oppositions, Merrill établit

5 Entre novembre 1897 et octobre 1898 , La plume avait inauguré une série d'articles concernant la littérature féminine du temps. Dans Le massacre des amazones, Henri Ner, émulant l'idée du massacre de Barbey d'Aurevilly, entreprenait une nouvelle croisade contre les bas-bleus, amazones « destructrices de la vraie littérature française » (Ner, 1897 : 694). 
aussi des rapprochements entre les images et les mots de trois grands noms contemporains : Noailles, Jammes, et Verlaine, sans qu'il ne reconnaisse pour autant le regard précis de Dauguet sur la nature, moteur des émotions individuelles et creuset collectif des traditions. La lecture de Merrill souligne l'opposition de Dauguet entre la modestie de son expression et la force ardente de la femme-poète imbue des rêveries de la musicienne.

Les dernières interventions de 1903 sur ce premier recueil terminent sur une mention qui nous révèle l'épistolière et la polémiste. Marie Dauguet écrit des lettres et l'un de ses destinataires est le polygraphe Maffeo Charles Poinsot ${ }^{6}$. Dans une rubrique de La Pensée intitulée « Conception moderne de l'art », Poinsot (1903: 3-8) répond aux « charmantes » lettres de $\mathrm{M}^{\text {me }}$ Dauguet dont il reproduit ici des fragments de son dernier échange. Dans cette « Réponse à Marie Dauguet », il expose ses avis, et les contradictions de cette poétesse reconnue par les critiques du temps (Régnier, Brunetière, Faguet et Stuart Merrill) dont il reprend les éloges pour mieux les contredire par la suite. La polémique entre Dauguet et Poinsot se base sur leur différente conception sur la nature de l'art et sur les rapports du peuple à l'art : pour elle, l'art est le produit « d'un déséquilibre mental » (Poinsot, 1903 : 2), « d'un état de grâce » (Poinsot, 1903:3), « une volupté douloureuse » (Poinsot, 1903: 4) : le peuple et la «plèbe intellectuelle » sont incapables de sentir l'émotion esthétique (Poinsot, 1903 :5). Pour Poinsot, l'inspiration ne suffit pas. L'art est sain, intelligent. La beauté est accessible à tous, et on ne saurait refuser au peuple le droit d'apprendre cette émotion, malgré la presse et le théâtre œuvrant à dévier le bon goût et la beauté (Poinsot, 1903 : 4). Il portraiture une femme aristocratique, hautaine, ennemie du progrès, et de la " plèbe intellectuelle » que démentent, d'un autre côté, la poétesse et sa poésie imbue d'« art de pensée sérieuse et humaine » (Poinsot, 1903: 6). Poinsot loue sa force de création mais dénonce ses partis pris esthétiques et sociaux en matière artistique. Poinsot a fourni ainsi un autre angle de vision pour analyser cette femme de lettres qui dépasse la seule image de la dame du terroir attelée à sa poésie jouissive d'une nature éternelle. Par ses pensées révélées dans cette lettre sur sa conception de l'art, elle prend place, dans la presse, au-delà de la poétesse, dans les courants d'opinion, dans la réflexion, et dans ce nouveau rapport au monde, qui passe par la communication médiatique moderne, qui se déploiera dans une culture médiatique en construction dès la Belle Époque (Mollier, 1997 : 15-26).

${ }^{6}$ Il s'étendra sur sa figure dans son Esthétique régionaliste (1911) et dans son petit livre sur L'art littéraire (1923), présentant Dauguet sous le jour de l'amour pour la terre et ses univers sensoriels. 


\subsection{Par l'amour (1904), le Prix Archon-Despérouses et les Clartés (1907)}

Membre de la Société des Poètes depuis 1903 (Anon., 1903 : 2-3), elle publie en 1904 le recueil Par l'Amour qui lui vaudra le prix Archon-Despérouses7 en $1905^{8}$ (Anon., 1905a : 10). Plusieurs poèmes du recueil avaient été publiés auparavant dans la presse, notamment en 1903. Le livre fait l'objet d'une dizaine de chroniques, d'articles et de comptes rendus. On retrouve une lettre de Dauguet, une dizaine d'extraits de Par l'amour, mais aussi certaines pièces qui seront ultérieurement réunies dans Pastorales (1909) car Dauguet écrit incessamment, indépendamment de la publication des recueils9. Mais c'est l'article de Rémy de Gourmont (1904 : 390-397) «Un poète de la nature », qui servira de préface au recueil, qui marquera un tournant dans l'étude de Dauguet.

Dès lors, ses propos seront repris à l'infini déployant l'image qu'il transmet de la femme « fermière, botaniste » (Gourmont, $1904: 392$ ), « optimiste » (Gourmont, 1904 : 396), « sérieuse » (Gourmont, 1904: 397) et le discours qu'il norme sur la poétesse (créatrices des images « odorales » (Gourmont, 1904: 393) et " poète sain » (Gourmont, $1904: 396)$. Il brosse un triple portrait de Marie Dauguet : la femme, le poète, le "poète fée » (Gourmont, 1904 : 392). Cette dernière idée n'a pas été retenue par la critique autant que l'idée du « poète de la nature » pour qui « tout lui est poésie, parce que tout émeut sa sensibilité » (Gourmont, 1904 : 392). Rémy de Gourmont inscrit définitivement dans l'histoire de la littérature cette « panthéiste » (Gourmont, 1904: 397) aux ardeurs sentimentales et aux effluves sensuelles, dénuée de mysticisme (Gourmont, $1904: 397)$. Pourtant sa conclusion est surprenante : Par l'amour représente « un moment de la sensibilité d'une femme » et « un recueil de beaux poèmes » (Gourmont, 1904: 397). Fallait-il que son examen se résolve dans des termes aussi généraux ? Franz Ansel reprend l'esprit des propos de Rémy de Gourmont et pour sa part, confesse une « fervente admiration » pour Par l'Amour, ce livre « captivant » (Gourmont, $1904:$ 723). Dans sa chronique « Les Poèmes » (Ansel, 1904 : 721-723), il confond critique et panégyrique. Ansel livrait à la postérité l'image d'une poétesse fantasque, à la plume puérilement émotive et trempée dans une encre décolorée. Le critique aurait dû entendre, ou pour

7 Prix annuel de poésie créé en 1834 par l'Académie qui lui est décerné lors de la séance du 18 mai 1905, sous la présidence de Paul Deschans (Anon., 1905b : [2]). Elle partage ce palmarès avec plusieurs poètes reconnus (Rivoire, Gregh, Clouzet, Nigond, Ferrières, Boutelleau, avec mention honorable, Hennique, Fons et Gaud).

${ }^{8}$ L'information sera reprise dans différents périodiques littéraires entre le 19 mai et la fin décembre 1904.

9 Plusieurs volumes de poésie et roman sont annoncés de 1902 à 1938 : L'éternel mirage, 1 vol. (Dauguet, 1902), Une Destinée, roman. 1 vol. (Dauguet, 1907, 1908a), Enlisée, roman, 1 vol (Dauguet, 1907), Au fond des bois au bord de l'eau, poèmes. 1 vol. (Dauguet, 1907, 1908a), Les Chants dyonisiens, poèmes 1 vol. (Dauguet, 1908a), La Maison-du-sonneur (Dauguet, 1938). Aucun de ces titres n’a été publié. 
le moins expliquer que cette poétesse du Beuchot, pétrie de lectures, de musiques, et de terroirs, avait su allier son goût pour la nature, ses inclinaisons pour l'écriture et la liberté de ses choix poétiques et idéologiques, au-delà des modes du temps. Dans une strophe citée par Ansel (1904: 723) il est affirmé qu'elle sera « bêtement tendre et sentimentale » (Dauguet, 1904 : 315).

Cette année-là, une autre série de mentions au recueil Par l'Amour et à Dauguet replace la poésie et la poétesse entre les grâces de son temps, et la réflexion sur les femmes et leur poésie. Dans une chronique anonyme (Anon., 1904b : [1]), Dauguet est à nouveau comparée à deux grandes femmes de lettres, Delarue Mardrus et $\mathrm{M}^{\mathrm{me}}$ de Noailles que la postérité d'ailleurs imposera à la poétesse comtoise. Elle est également célébrée comme la muse d'une " sévérité classique », chantre des impressions de la nature, de la « vie simple et pure de la campagne » (Anon., 1904b : [1]). Quant à « S. » (1904:3), il récupère l'idée de l'âme du poète entraînée par la nature, enivrée de panthéisme. Cette fois la comparaison avec Noailles tourne à l'avantage de Dauguet : l'intensité et l'authenticité de sa poésie se combinent à la folle sagesse du poète $(S, 1904: 3)$.

Dauguet occupera effectivement une place de choix dans la poésie des femmes et le discours critique correspondant dans un temps où selon une partie de la critique journalistique "Orphée change de sexe » (Anon., 1904a : 5-6) et les cohortes "des femmes-auteurs » (Marion, 1904: 2) « s'avancent, en bataillon serré » (Deschamps, $1904: 2)$. Selon le premier chroniqueur, Orphée deviendrait Sapho à l'insu de la fracture qui divise la poésie française contemporaine en deux mondes : un parnasse masculin faible comblé de "politiques, journalistes, romanciers et hommes de théâtre déchus » ( « Coppée, Deroulède ; Mendés, Lorrain, Tailhade ; Louys, de Régnier ; Bataille, Rostand, Moréas » (Anon., 1904a : 5) et un parnasse féminin naissant associé à des poètes consacrés : Noailles serait Hugo; Delarue-Mardrus, Lamartine ; Dupuy, Verlaine ; Renée Vivien, Baudelaire ; Dupuy, Verlaine ; et Marie Dauguet devient Vigny (Anon., 1904a : 5-6). Mais ne nous méprenons pas, le critique établit une filiation masculine pour cautionner les créatrices, et s'interroge, non sans malveillance, sur l'avenir incertain de la poésie qui se joue pour « les nouvelles poétesses » dans les pages de la presse du temps (Anon., 1904a : 6). Ce procès aux femmes poètes est à vrai dire un procès aux femmes tout court. Deschamps, lui, n'hésitera pas à ironiser sur les listes de " prosatrices (Noailles, Hayy, Strannik, Leblanc, Serao)» et de " poétesses (Noailles, Vacaresco, Rostand, Daudet, Dortzal, Kaiser, Comert, etc.) » constituant des sortes d'échantillonnages offerts à l'Académie pour choisir les " académiciens en jupe », et ainsi « charmer la coupole » (Deschamps, 1904 : [2]). Le temps n'était pas encore venu pour élire une académicienne. C'est aussi dans ce sens que Paul Marion (1904 : 2) inscrit sa chronique. Ce sont les poétesses qui s'imposent parfois, grâce à leur savoir-faire dans la versification et une certaine innovation, sans pour autant renoncer aux formes classiques. Ici encore, les listes se 
multiplient et les « confrères en culottes (Fernand Gregh, Henri Barbusse, Maurice Magre, Sébastien-Charles Leconte, Louis Legendre et Fernand de Fleury) » s'opposent à leurs " émules en jupon (en prose, Tynaire, Harry, Leblanc et en poésie : Noailles, Vacaresco, Rostand, Daudet, Dortzal, Dupuy)» (Marion, 1904: 2). Et de culottes en jupons, c'est sur Marie Dauguet en particulier que l'on s'arrête. En s'inspirant en partie de l'article de Gourmont (1904 : 390-397), le critique loue "l'élégance et l'harmonie » de son dernier recueil. Il revient sur sa passion de la nature et son goût pour les parfums. Selon lui, une certaine mièvrerie sera rattrapée par un panthéisme sensuel et ardent (Marion, 1904:2). Il en éclaire aussi les défauts, tels que la paraphrase d'Anacréon et l'utilisation du vers libre (Marion, 1904: 2). Finalement, il s'interroge sur la capacité de Dauguet, et des femmes, à accepter les critiques, trop indifférentes, selon lui, aux recommandations masculines, trop influencées par un féminisme malveillant. La stigmatisation du féminisme émancipateur faisait son chemin, et le blâme à la désobéissance des femmes se poursuivait.

En décembre 1904, Françoise Benassis signe une chronique des livres consacré à la littérature et aux femmes, au féminisme et à l'acclamation du talent de Marie Dauguet annoncé dans À travers le voile et confirmé Par l'Amour. Sa défense d'un féminisme de "lumière et de progrès » éclairant la femme nouvelle d'un " courage d'analyste » (Benassis, 1904:3) et de la volonté de se refaire est précédée d'une critique à la férocité d'une grande partie des femmes écrivains jugeant leurs consœurs. Paradoxalement, elle n'établit aucun lien avec les qualités des femmes de lettres en général, ni avec Marie Dauguet en particulier. Quant à sa poésie, elle reprend le cliché de l'inspiration de la nature, sa haute culture de poète, de peintre et de musicienne. Elle n'oubliera pas de citer quelques mots de Gourmont (Benassis, 1904 : 3). Benassis n'apporte aucune nouveauté et s'accorde sur certains défauts du recueil signalés par d'autres critiques, notamment l'abondance d'intertextes, la lourdeur formelle, le simplisme bucolique (Ghéon, 1904 : 309), les erreurs de versification, les multiples néologismes (Foley, 1904: 2), l'abus des sensations et l'« étrangeté blessante » de certains de ses vers et de ses mots (S., $1904: 3$ ). Pour Quillard (1904 : 199-201) aussi, la simplicité des images et des thèmes se double d'une certaine distraction dans la composition, d'un excès de formules surannées, de jargons et patois et de transpositions d'auteurs anciens (Lucrèce, Virgile, Théocrite) et modernes (Ronsard, Jammes, Vigny, et Loïsa Puget, compositrice de chansonnettes et de romances). S'inspirant en partie du préfacier, Quillard (1904:200) rappellera à Dauguet de ne pas oublier le don « des fées heureuses » que Gourmont (1904 : 392) lui avait octroyé.

Marie Dauguet n'apprécia ni les blâmes ni les mérites et elle répondit au directeur du Mercure de France qu'elle connaissait bien. Au grief de l'absence d'émotion (Dauguet, 1904a : 722), Dauguet oppose la violence des élans qu'elle éprouve et l'« ivresse panthéiste » qu'elle veut transmettre. Elle 
nie toute imitation, sauf celle de Ronsard, son maitre de la poésie de la nature et de la langue ancienne (Dauguet, 1904a : 722-723), et revendique ses sources : Jammes, Desbordes-Valmore, Latouche, Soulié, Sainte-Beuve, entre autres, les romances, les vieux refrains, la musique et les chants populaires des veillées et les salons parisiens. C'est une lettre émotive qui exprime la déception de n'avoir pas su toucher l'âme du lecteur mais c'est surtout un document éclairant la poétique de la poétesse et la véhémence de la femme qui défend avec passion et force d'arguments son écriture, sa démarche créatrice et ses sources.

Ses talents et son énergie seront d'ailleurs récompensés. À partir de sa réception du Prix Archon-Despérouses, en 1905, les jugements sur la poétesse redoublent: pour certains, il s'agit d'un choix par défaut (ErnestCharles, $1905:$ : 1]) ; pour d'autres, il récompense une bonne « interprète des paysages agrestes » (Pip, 1905: 414). Quoi qu'il en soit, elle revient au cœur du débat de la place des femmes en littérature. Pour sa part, Ansel (1905 : 226-226) reprend la parole pour s'exprimer sur À travers le voile. Cette fois, il sera moins hyperbolique qu'en 1904 (Ansel, $1905:$ 721-723), et restera plus proche de la franc-comtoise. À cet effet, il consacre une partie de son article au souvenir d'un voyage en Franche-Comté pour mieux analyser la poétique de Dauguet basée sur « l'émotion lyrique » et les « charmes champêtres » (Ansel, 1905: 226). Il reprend l'idée des " transpositions » (chansons folkloriques, musique, romanesque) (Ansel, $1905: 226$ ) qui irriguent ce livre de nuits et d'aubes, de forges et d'enclumes, de cours d'eau et de bois, de senteurs et de saveurs. Le critique a interprété l'esthétique rustique pour y saisir l'« amertume de la pensée humaines » (Ansel, 1905: 226). Mais Ansel reste imprécis quant à la conception formelle de son écriture qu'il réduit à deux adjectifs «harmonieuse et attrayante » (Ansel, 1905 : 226). Pour sa part, Henri Liebrecht (1905 : 253-254) s'inspirant amplement de « la judicieuse préface » de Rémy de Gourmont et de l'idée du panthéisme de Dauguet, apporte cependant un point de vue différent pour son analyse de Par l'Amour. Il oppose la poésie champêtre de Marie Dauguet à la faiblesse de la poésie de la nature de son temps (artifices et conventions littéraires). Sensibilité, conscience et raison composent sa conception organiciste de la nature que Liebrecht $(1905: 254)$ signale comme une " science de vivre » aboutissant à ce nouvel ars amandi où Bossuet aura le dernier mot.

En 1906, entre janvier et décembre, Marie Dauguet apparaît dans la presse d'une façon plus accidentelle : on ne retrouve aucun compte rendu spécifique sur son ouvre. Cependant, de nombreux poèmes paraissent en particulier dans L'Ermitage et les mentions à la poétesse se multiplient dans les revues de presse, les articles et des chroniques renvoyant à des prix, des enquêtes et à la question des femmes et de la littérature. Notamment, l'article des « Femmes de lettres » de Firmin van den Bosch (1906 : 136-140) revient sur la révolte bas-bleuiste et dénonce les femmes féministes qui écrivent et prétendent à l'intellectualité. Le critique place la lecture de Par 
l'Amour à la suite de ses consœurs belges (Marie Closset, Blanche Rousseau et Hélène Canivet). Le portrait tourne à l'avantage de Dauguet, et le critique lamente l'indifférence dont Marie Dauguet est encore victime. En mars 1906, Le Petit Moniteur publie une chronique anonyme consacrée aux femmes poètes : Marie Krysinska, Marie Weyruc, Cécile Perrin et Lucie Delarue-Mardrus. L'article développe la question de l'importance de la femme dans la littérature contemporaine, la généralité de ses faiblesses poétiques et établit des listes. Le bilan critique est sans originalité : les femmes en littérature apparaissent de nouveau déterminées par leur nature émotionnelle exacerbée, sous les formes réputées féminines de « la mélancolie », de « la grâce », de « la sensibilité ».(Anon., $1906:$ [3]).

En 1907, la librairie Émile Sansot édite et publie les Clartés. Notes et pochades. Italie. Printemps et été 1905. L'ouvrage fera l'objet de plusieurs comptes rendus. André du Fresnois (1907: 1042-1043) met en valeur ce nouveau recueil basé principalement sur le « sens de la terre » (Du Fresnois, 1907 : 1041), qui s’insère, pour lui, dans le cadre de la littérature écrite par les femmes, où leur identité se retrouve en creux. Dauguet se soustrait toutefois au reproche fait à la l'écriture féminine autobiographique en ignorant son vécu pour mieux livrer ses « impressions sincères » sur les villes italiennes qu'elle traverse (Du Fresnois, 1907 : 1043). Pour Du Fresnois (1907 : 1042), elle fait honneur à son érudition, à l'énergie et à la liberté de sa création. Elle confirmera à Séché sa démarche littéraire : l'émotion, l'inspiration et enfin la raison « qui corrige, organise, équilibre » (Dauguet, [1908b] : 60). Pour le critique belge Arnold Goffin (1907 : 412), tout l'intérêt des Clartés est dilué dans une suite de clichés poétiques sur l'Italie où divinités et mythes rivalisent avec le lyrisme parfumé de Rome, Florence et Naples. Parmi ces formules étiolées, Goffin (1907 : 412) aura su reconnaitre un paganisme « d'esprit et de tempérament » de la poétesse, sur lequel reviendront, entre autres, Faguet (1908:68) qui le qualifiera de "paganisme de pacotille » et Jean de Gourmont (1910: 30) de « paganisme bucolique ».

En avril, Jean Ott (1907: 106) émet un avis partagé sur les Clartés qu'il range aux rayons des « croquis ». La dénomination ne manque pas de justesse si l'on considère les rapports de l'auteur à la peinture et la composition mixte de ce recueil dont les tableaux des voyages italiens perlent la prose de quelques pièces en vers qu'il juge « alambiqués » (Ott, 1907:107). Si la sensualité s'impose à nouveau pour définir la poétesse, cette fois elle concerne aussi la femme, frémissante, selon Ott (1907: 107), comme une « orientale lourde de joyaux ». Il ajoute à l'imagerie décadente celle de la « voyageuse lyrique » (Ott, $1907: 107)$. Dauguet n'a jamais prétendu à une poétique matérialiste mais à la pure beauté de la nature, et à la nature des hommes, des femmes et de leurs passions. En cela, les propos de ce critique permettent de dépasser le commentaire de Rémy de Gourmont, élargissant les horizons de lecture de la poésie de Dauguet vers les abîmes plus profonds de l'esprit. Il faut reconnaitre à Ott le mérite de montrer une femme sous le 
double prisme de la voyageuse et de la penseuse, sauvant Dauguet d'une certaine mollesse intellectuelle qu'on lui attribue trop aisément.

Le même mois, la section de « Bibliographie » de la Patrie salue dans les Clartés ou «impressions d'Italie » l'avènement de Dauguet, femme de talent et d'esprit, la beauté des sonnets consacrés à Florence et de la prose racontant Sorrente (Anon., 1907 : 4). Mais le critique anonyme blâme ici ce que Ott avait loué : trop d'impressionnisme pictural et musical au détriment d'une écriture littéraire négligée et d'une certaine lourdeur. À nouveau, le jugement rejoint le débat sur les femmes en littérature : mais il ne s'agit plus de souligner leur infériorité ou leur supériorité par rapport aux poètes ; dans ce cas-ci, c'est l'amoralisme de la femme de lettres qui est ciblé et la liberté d'expression et de conscience qu'on leur conteste sans ambages. En mai 1907, Maurice Cabs analyse les Clartés (1907 : [1]). Il connait sa poésie, dont il a étudié À travers le voile (Cabs, 1902 : [1]), et il apprécie la sérénité et la simplicité de la langue employée, forte de "vérité » et de "vie » (Cabs, 1907 : [1]). Il souligne l'expression des sentiments dans cet éloge de la vision claire des beautés italiennes formant un « carnet de voyage », mi prose, mi vers, imprégné de "sensibilité féminine »(Cabs, 1907: [1]), et dénué de tout fil directeur. Cette appréciation de Cabs est contestable. Car point de dispersion, ni d'improvisation dans cette succession de séjours italiens dont le fil d'Ariane est tendu par le regard observateur de la voyageuse, et la cohésion assurée par son écriture précise et critique. En juin 1907, dans un examen sommaire, Pierre de Saint-Jean (1907:4) se penche sur les Clartés en reconnaissant le talent de Dauguet pour mieux exprimer sa haine du basbleuisme. Quant au recueil, le critique, rejoignant Cabs, a bien remarqué que l'alternance de vers et de prose rend compte des différents espaces traversés, villes et campagne, mais aussi des mœurs, des usages et des coutumes.

Finissons par le compte rendu d'avril 1907 de Jean de Gourmont de Clartés dans la section « Littérature ». La dernière partie de son étude apporte une autre nouveauté : Marie Dauguet cesse d'être une conteuse de sensations et d'impressions pour être découverte comme une critique d'art qui préconise « un esprit critique dégagé de toute suggestion » (Gourmont, 1907 : 502). Pour Gourmont, Dauguet fait preuve d'audace dans ses jugements esthétiques sur la littérature et sur les arts, en particulier dans trois des chapitres consacrés à Rome. Il complète ainsi son portrait par cette dimension de critique, incontournable pour comprendre l'ampleur du savoir de Dauguet, de ses lectures et de sa conception (poétique) du monde. À ce titre, le catalogue de dédicaces et de citations contenu dans ses œuvres reflète moins une recherche de garantie d'autorité que la volonté de se forger une position intellectuelle, de lettrée, pour soutenir ses arguments, pour enrichir sa pensée, pour dire le monde. Ses jugements esthétiques pourraient traduire cette recherche d'une élite féminine de la Belle Époque. Dauguet n’a jamais poursuivi le succès, « seule l'élite l'importe » écrira-t-elle à Quillard en 1904 (Dauguet, 1904a : 723). 


\section{1908-1914 : une apogée incertaine}

L'année 1908 semble porter moins de fruits que les précédentes : dans le corpus sélectionné, nous n'avons détecté que trois comptes rendus consacrés à la poésie de Marie Dauguet. Faguet (1908 : 68-70) et Kahn (1908 : 2) s'attarderont sur les Clartés publié en 1907 ; et Albert Saint-Paul (1908 : 6) sur les Pastorales venant de paraître.

Faguet revient sur un premier jugement favorable à Dauguet : dans une rubrique consacrée aux « Poètes » (Thédenat, Paul Soniès, Henri de Régnier, Jean Moréas, Jean Picard, Hélène Picard, et Ernest Dupuy), il examine Clartés. Sa chronique est le récit d'une déception en deux temps: d'abord la prose, où, selon lui, tout n'est que " paganisme de pacotille » et où Nietzsche est « mal compris » (Faguet, 1908 : 68). Ensuite la poésie, dénuée de rythme et d'harmonie. Il tempère la négligence formelle en reconnaissant un certain talent pour dire les sensations et les sentiments (Faguet, 1908 : 69), hérité de Chénier (Faguet, 1908 : 70). En revanche, pour Gustave Kahn (avril 1908 : [2]), le recueil des Clartés confirme le talent de Marie Dauguet. Aux moissons de la terre et aux émois de la chair, il ajoute ici la reconnaissance d'un " souffle lyrique » qui innerve la "vision précise des choses des champs et de la forêt » (Kahn, 1908 : [2]). Par ailleurs, Kahn (1908 : [2]) insiste sur la «passion personnelle » du lyrisme de Dauguet, nourri de nature, de force poétique et de « volupté de vivre ». Dans ce sens, il confirme que Dauguet, au même titre que Madeleine Paul, Anna de Noailles ou Hélène Picard, incarne la présence des femmes dans le Parnasse, dépassant leur ancien statut d'égérie. Mais le juge devient censeur et invite les poétesses à modérer leur « frénésie » lyrique (Kahn, 1908 : [2]). Encore une fois les vers de Marie Dauguet, sa poétique et ses images s'estompent au gré de cette réflexion ultime que le critique consacre à la question des femmes et à leur capacité poétique.

En 1909, de janvier à août Les Pastorales, fera l'objet de plusieurs comptes rendus. Pierre Nothomb (1909 : 446-450), collaborateur assidu de Durendal, poète de l'amour et de l'inspiration biblique (Mortier, $1990: 1$ ) examine le recueil à la lumière de ses propres postulats. Pour le baron, Dauguet n'est ni virgilienne, contrairement à l'opinion communément admise de la critique, ni chrétienne, comme le reste des poétesses du temps. Cette double négation est la base de son analyse qui cherche à souligner le " panthéisme passionné » de Dauguet (Nothomb, 1909:446) et de préconiser sa christianisation en interprétant telle une ferveur religieuse de la nature son lyrisme mêlant la nature, le quotidien, les sensations et les émois du corps, de l'âme et de l'esprit. Pour sa part, Pierre de Saint-Jean (1909 : 53-54) conclut son article sur Les Pastorales (qu'il juge supérieur à ses Clartés) par des vers illustrant son langage figuratif qui poétise une nature grâce à des images inattendues allant de l' " abeille enivrée » à l' « hymne d'or des blés » pour sombrer dans une "glèbe où le soleil s'écroule " (Saint-Jean,1909: 54). Pour Ernest-Charles (1909: 797-801), Dauguet est une poétesse de la nature et les Pastorales s'inscrivent dans le panthéisme oscillant entre le 
paganisme, le mysticisme et l'érotisme. Les différents critiques s'accordent à des degrés divers sur la doctrine panthéiste et l'amour de la nature, en incorporant des éléments nouveaux sur Dauguet et sa poétique dans certains cas.

Le Goffic (1909 : 263-265), dans sa chronique « Nos poètes », met en valeur deux éléments qui lui tiennent à cour : le régionalisme et la poésie féminine. Pour ce critique, les trois recueils de Dauguet (À travers le voile, Par l'Amour, et Les Pastorales) se ressourcent dans la nature franc-comtoise mais Les Pastorales traduisent une veine érotique qu'il associe à la nature créatrice féminine. Si pour Le Goffic, cette poétesse du terroir et de la nature renvoie à l'idée de la fécondation assimilant création, poésie et « état féminin ${ }^{10}$, un critique anonyme (1909: [2]) met en avant l'effet thérapeutique de la poésie panthéiste de Dauguet. Dans ce cas, l'expérience de la nature telle qu'elle est vécue, éprouvée et poétisée par Dauguet est présentée par ce critique comme un modèle sociétal et esthétique apaisant « l'âme moderne " et ses regards désabusés oublieux des " rêves anciens » (Anon., 1909 : [2]). C'est dans ce double jeu de l'Ancien et du Moderne, que Marie Dauguet a toujours écrit la jouissance d'être au monde, par une nature sensuelle cautionnée par la tradition d'Éros et de Thanatos. C'est dans ce sens que se prononce Tresserre (1909:38), poète de l'école toulousaine dont la chronique intitulée "L'enclos des Poètes » s'achève sur quelques lignes consacrées aux Pastorales. Tresserre (1909: 37) aura compris que le «panthéisme fervent » de Dauguet n'est guère une leçon de morale mais qu'il relève de l'élan voluptueux qu'elle éprouve envers la terre. Paganisme et mysticisme s'entrecroisent dans la chaîne infinie de mots pour dire l'énergie de la nature, la jouissance de vivre, sans souci de rédemption, entre la prière et le blasphème.

En mars 1909, Quillard (1909: 306-307) s'attache à l'examen des Pastorales après s'être penché sur deux de ses recueils précédents. À cette occasion, il sera plus favorable à l'art de cette « muse robuste et splendide » et louera, malgré son patois, son «excellent français » (Quillard 1909: 308). Pour lui, le panthéisme de Dauguet est une sorte d'« orphisme rénové » chantant le monde sensoriel, la volupté de vivre, et la beauté du monde (Quillard 1909 : 307). Dans Les Pastorales, Quillard estime que sa poésie s'enrichit de nouvelles lectures et d'une vision mieux organisée de ses univers poétiques, sans perdre la fraîcheur de son goût pour une nature totale. Cette "féerie universelle» (Quillard 1909: 306) s'enrichit alors de deux autres images mythiques, celle des travaux et des jours et celle de

${ }^{10}$ Quelques années plus tard, il reviendra sur cette idée pour dénigrer la poésie féminine du temps (Le Goffic, 1912), qu'il n'abordera d'ailleurs pas dans sa Littérature française (1919). 
l'exaltation. De cette sorte, la conteuse rejoint Hésiode et la poétesse rencontre Dyonisos ${ }^{11}$. C'est là une caractéristique de premier ordre : le syncrétisme de Dauguet ne doit pas être négligé dans sa poétique. Son art est inconcevable sans la fusion de la peinture et de la musique (Dauguet, [1908b] : 60 ) et sans ses sources, nous l'avons vu.

En mars 1909, dans ses « Notes » bibliographiques, Schlumberger (1909 : 94-96), l'un des fondateurs de la Nouvelle Revue, sera sévère en regard des Pastorales de Dauguet, et sans pitié pour les femmes poètes et leur tendance au panthéisme par défaut. Pour lui, de Sapho à Desbordes-Valmore, le pouvoir créateur des femmes relève de leur démesure naturelle, dépourvue de « la virile maitrise », contrainte par le devoir (féminin) de pudeur et un savoir incertain. Par ailleurs, il détermine que la fantaisie est la ressource féminine majeure pour créer, ainsi que les philosophies de passage - notamment le panthéisme. C'est dans ce contexte de constriction, de résignation, de fragilité et d'évanescence que Schlumberger inscrit les femmes, leurs œuvres et, donc Les Pastorales. Le critique qui reconnaît le panthéisme et l'objectivisme de Dauguet, signale certes ses quelques réussites de vocabulaire rustique et la force de sa poésie habitée par « l'âme vibrante et forte de la terre » (Schlumberger, 1909: 90). Mais, en dernière instance, c'est la faiblesse de sa construction qu'il met en lumière en évoquant « une armature de médiocre qualité » (Schlumberger, 1909 : 96).

En mai 1909, dans la section des "Variétés », le critique du Journal des Débats, Henri Chantavoine (1909: 3) s'écarte du ton tranchant de Schlumberger. Il consacre un article aux Pastorales composé sous le double prisme du critique et de l'ami. Il relève trois dimensions dans l'expérience de Dauguet : l'émotion, la pensée et le récit qui s'attache à « tout et sans rien mépriser » (Chantavoine, 1909:3). Si ces observations sont réitératives, Chantavoine a su comprendre que l'élan de mystère du recueil concerne d'une part l'analogie entre Les Pastorales et les Travaux et les jours d'Hésiode, et d'autre part, la sympathie de la poétesse pour les petites gens des campagnes. Il rejoint en cela Rémy de Gourmont (1904 : 392), Nothromb (1909: 450) et Charles (1909: [1]), respectivement, selon lesquels pour Dauguet rien n'est vulgaire ou indigne dans la nature car tout est digne d'être poétisé, en vers, en vers libre, en prose. Pour une fois, au-delà de constater des défauts de forme (une versification "inouie », " négligée »), des images violentes (Chantavoine 1909:3) et d'évoquer le seul stade de l'esthétisme panthéiste de Dauguet, Chantavoine situe la poétesse dans sa complexité littéraire. Ses propos permettent de réajuster son portait, de se rapprocher de ses enjeux esthétiques et de son idéal littéraire, qu'elle-même formulait ainsi en 1908: "Le goût de n'être que moi dans l'expression comme dans l'idée » (Dauguet, [1908b] : 60).

Mais en 1909 elle est jugée de la même manière que le mouvement littéraire féminin, entre la louange et le blâme. Si elle incarne la poétesse de

${ }^{11}$ Pour qui elle avait prévu de composer un recueil intitulé Les Chants dyonisiens annoncé dans Les Pastorales (Dauguet, 1908a : s.p.) 
son temps (Schlumberger, 1909 : 94-96), l'excellent poète (Cazet, 1909 : 2), placé au plus haut rang du Parnasse, elle donne aussi dans la regrettable erreur du vers libre (Charles, 1909: [1]). Si elle partage le « premier rang des autrices du temps » (Saint-Jean, 1909: 54), elle occupe un jalon inférieur aux poétesses de la nature de cette époque, notamment Hélène Picard et $\mathrm{M}^{\mathrm{me}}$ de Noailles (Cazet 1909: 2) qu'elle rejoint toutefois en termes de " simplicités potagères » (Praviel, 1909: 551) et de «traité d'agriculture » (Saint-Point, 1909: 4).

Deux ans après sa parution, le recueil des Pastorales fait encore l'objet de plusieurs comptes rendus. Pour Henri Martineau (1910 : 245]) dans sa section «Les Poèmes », Les Pastorales représentent l'amour frénétique des champs, des jardins, et de leurs travaux. Il retient l'appartenance de cette femme cultivée à l'école de Baudelaire et des symbolistes et sa maîtrise des correspondances des sons et des parfums. Dans sa « Quinzaine littéraire de Gil Blas », Pierre Corrard consacre aux Pastorales une lecture critique qui développe le panthéisme de Dauguet, insiste sur sa similitude avec la comtesse de Noailles (en termes de sensibilité et de sensualité), et mentionne une poétique que justifie sa nature de femme (instinctive et naïve). Pour sa part, Paul Abram (1910 : 2) souligne la qualité lyrique du recueil et présente Marie Dauguet comme la chanteuse primesautière d'une campagne odorante de «foins coupés » (Abram, 1910:2). En octobre 1910, Pierre Valdagne (1910 : 2) consacre aux Pastorales les dernières lignes de sa longue causerie sur les livres nouveaux du moment. Il s'agit d'une relecture qui lui offre l'occasion d'affirmer l'excellence d'un poète et les bontés « colorées » et "passionnées » (Valdagne, $1910: 2$ ) d'un recueil dédié à Virgile et à la nature. Pour lui, Dauguet s'applique à poétiser une nature champêtre que le critique rattache à deux images significatives : « le potager » et « la bonne santé » (Valdagne, 1910: 2). Il revient sur l'inscription des Pastorales dans la tradition de la poésie horticole de l'Antiquité. Pourtant, il relève un nouvel enjeu de cette poétique : l'image idyllique du jardin cultivé par les Muses s'estompe à la faveur de celle de l'enclos familier et quotidien, maîtrisant flore et faune, au bénéfice de l'apaisement des corps et des esprits. C'est pourtant dans cet ordre de choses qu'il conviendrait de comprendre une chronique de l'Académie des Sciences, des Belles-Lettres et Arts de Besançon (Anon., 1910 : 184) qui rend hommage à une Marie Dauguet habitante du Beuchot, femme cultivée, lauréate de l'Académie, et cultivatrice poétique de sa campagne franc-comtoise. À cet égard, le rapprochement entre la poésie de Delille, pour qui la nature est objet de science, d'agrément et de savoir, et celle de Dauguet favorise la rencontre de la poésie scientifique du premier, la libido sciendi, et la libido sentendi des Pastorales. La poétesse rejoint à nouveau le haut lignage de la poésie rustique de Lucrèce, de Virgile, d'Homère jusqu'à Ronsard, au Tasse, ou à Milton.

En 1911, les éditions Sansot publient L'Essor victorieux, qui connaîtra deux éditions, dont les exemplaires sont pratiquement introuvables. Dans un premier temps, les comptes rendus placent L'Essor victorieux sous 
le signe des influences de Baudelaire et de Nietzsche, et des contrastes, notamment dans le domaine des concepts de féminité et de masculinité appliqués à la littérature. Pour Martineau (1911 : 313-315), L'Essor victorieux confirme la poétesse du romantisme féminin, contrairement à ce que pense Veyssié (1911b : [3]), et du renouveau naturiste, dont la versification négligée traduit la passion et la sensualité. Il rappelle ses sources baudelairiennes que nuancent des « accents sadiques » (Martineau, $1911: 315$ ), plaçant ses images de la nature entre la lumière et l'ombre, entre la joie et la tristesse, entre les délices et les souffrances. Pour Martineau, cet univers antinomique se ressource dans la dualité d'Éros et de Thanatos et détermine l'énergie de cette poésie, peut-être trop « virtuose » et alourdie par trop « de termes rares » (Martineau, 1911: 316). Pourtant, le critique convient aussi que sa poésie est une « envolée » (Martineau, 1911 : 316) dont la victoire réside probablement dans cet espoir inexorable d'une liberté totale de pensée et d'être au monde grâce à une création qui articule sensations et choix minutieux des mots. La perspective de Martineau éclaire la volonté poétique de la poétesse consciente de la littérature comme un événement des langages. Marie Dauguet a d'ailleurs des convictions poétiques (Dauguet, 1904a : 721-723).

Pour sa part, Héra Mirtel cite Dauguet et son Essor victorieux dans son compte rendu de la conférence de $\mathrm{M}^{\mathrm{me}}$ Aurel (1911) faite à la Maison des Étudiants qui porte sur la conception féminine du théâtre, reflet « du vrai lyrisme féminin » (Mirtel, $1911: 3$ ). Mirtel associe alors pureté et beauté féminine par opposition à la productivité masculine et sa laideur. C'est dans ce contexte qu'elle convoque d'autres femmes de lettres, notamment Périn et Dauguet. Pour elle, L'Essor victorieux illustre la victoire du féminin et de la nature, et de la beauté, imperméable à tout artifice. Quelques jours plus tard, dans la section des « Échos » de Comoedia, Le Masque de Verre place de nouveau le recueil sous le double signe de la masculinité et la féminité : c'est un recueil d'une "beauté virile », encore, mais « inconcevable », toujours, pour une femme poète (Mirtel, 1911:1-2). Ces qualificatifs évoquent la représentation du masculin et du féminin dans l'écriture (Planté, 2002 : 5-14) et la reconnaissance de l'exception artistique chez cette poétesse d'un cloisonnement genré des catégories éthiques et esthétiques, dévaluant la femme poète par l'utilisation de valeurs masculines. Malgré tout, une partie de la critique capte les vertus de ce petit chef-d'œuvre aux richesses verbales et thématiques intronisant la nature et la sensibilité (Le Wattman, 1911 : [2]) et loue les qualités de l'œuvre d'art et de passion (Anon., $1911: 2$ ). Mais ce sont sans doute les articles de Veyssié qui examinent L'Essor victorieux et Les Pastorales qui synthétisent le mieux la poésie de Dauguet.

Avant de publier son article sur L'Essor victorieux, Veyssié (1911a : [3]) fait l'éloge de Sansot, éditeur moderne et audacieux, capable de publier des poétesses comme Burnat-Provins ou Dauguet à qui il consacre de nombreuses lignes en 1911. Face à la poésie de bergeries de l'ancien temps, Veyssié (1911a : [3]) oppose une vision de la poésie contemporaine inspirée dans la nature, qu'il rattache à la contemplation du monde contemporain, 
ses bouleversements et ses fractures. Dans cet ordre de choses, selon lui, les muses célébrées sont Delarue-Madrus, la comtesse de Noailles, et en particulier Marie Dauguet.

En juillet, il publie deux articles (Veyssié, 1911b et c : [3]) sur le poète de la nature qui constituent en fait un compte rendu des Pastorales (Veyssié, 1911b et c : [3]) ${ }^{12}$. Pour Veyssié, elle représente le modèle de poète de la nature et ses Pastorales, dénués de " romantisme et gongorisme », le confirment (Veyssié, 1911b : [3]). À partir de ces prémisses, son essai sur Les Pastorales apporte une vision plus précise de sa poétique. Pour le critique, ce chef-d'œuvre de Dauguet est l'expression achevée de la force de son tempérament libre et du génie de son écriture poétique. Une écriture qui exalte la nature vivante sous toutes ses formes ( «tourmentée, ravagée, sauvage ») (Veyssié, 1911c : [3]), provoque la plus haute sensualité, et convoque les tourments de la chair et les émotions de l'âme. Par ailleurs, « sa passion de la nature » (Veyssié, 1911c : [3]) est vécue au quotidien et se nourrit des petites choses. Veyssié (1911b : [3]) nuance sa lecture éclipsant alors « l'âme agreste et robuste » de la poétesse au bénéfice de la silhouette de la bergère, entourée de "ses troupeaux, de ses prairies, de sa glèbe » (Veyssié, 1911c : [3]). Il se rapproche alors de Jean Dornis, comparant Marie Dauguet à une «fermière qui vit les pieds sur le sol »(Veyssié, 1911: 1). Tous deux aboutissent à la même conclusion sur le panthéisme de la poétesse. En ce qui concerne la forme, Veyssié rejoint ses confrères, et signale une pléthore stylistique que justifie l'objet même de cette poésie destinée à transcrire les mille et un frémissements de la nature. Entre la perfection et le génie, Veyssié (1911c : 3) est formel : " Marie Dauguet a du génie ».

En août 1911, il reçoit une lettre de Dauguet datée du 12 du même mois (Veyssié, 1911d : [3]) : elle est en train de terminer ses corrections de L'Essor victorieux dont elle précise que ce livre représente « l'essentiel et la sincérité » d'elle-même " hors du faux lyrisme et du faux romantisme » (Dauguet, 1911-: [3]). En octobre, Veyssié (1911e : 3) annonce le nouveau livre du « poète panthéiste des Pastorales » dont il publie le compte rendu un mois plus tard. Il nuance ses éloges (Veyssié, 1911f : [2]). En ce qui concerne la forme (Veyssié, 1911f : [2]), il critique à nouveau le dilettantiste, et en particulier l'usage du sonnet qui contraint la force de son expressivité voluptueuse. Paradoxalement, Veyssié se plaint alors de ce qu'il refusait aux Pastorales : "J'eusse voulu qu'elle fut [...] immodérément voluptueuse » (Veyssié, 1911f : [2]).

Plusieurs comptes rendus consacrés à L'Essor victorieux paraissent en 1912. Le premier est signé par Henriette Charasson (1912:376-380) pour qui Dauguet est « une poétesse des plus intéressantes » (Charasson, 1912 : 380) de son temps. Sa lecture critique sépare définitivement le monde et l'art en univers d'hommes et des femmes, en poètes exercés et en poétesses nouvelles. Pour Charasson, Dauguet n'est pas une panthéiste, c'est l'homme

${ }^{12}$ Il développera cette lecture en 1912 dans son anthologie (Veyssié, 1912 : 35-41). 
qu'elle aime dans la nature, et Colette est plus juste dans sa peinture de la nature. La critique est implacable à l'égard des femmes en général et de Dauguet en particulier : certains de ses vers la gênent par leur érotisme, par leur « exhibitionnisme moral » (Charasson, $1912: 378)$. Charasson (1912:380) regrette trop d'extase charnelle chez Dauguet, mais loue sa passion de la vie, son horreur de la mort, et sa « mystique de la chair »13.

Face à ces redites, dans sa chronique sur les poèmes du temps, analysant L'Essor victorieux, Georges Duhamel (1912: 138-139) rappelle que l'amour en est le thème principal, la nature, son « décor unique » (Duhamel, 1912 : 362), et la sensualité, le lien qui les soude. Son jugement apporte deux éléments nouveaux dans la lecture du recueil et de Dauguet : les ténèbres et la violence. L'Essor victorieux c'est aussi une " violence efficace » (Duhamel, 1912 : 362) que Duhamel définit comme l'expression de l'ardente sensualité de sa religion d'amour, faite de chair et d'âme, enveloppée de lumières crépusculaires et qui décline l'énergie de la passion dans des images de force et de fureur. Dans les quelques vers cités, l'image prométhéenne de « l'ange et l'animal » rejoint alors l'univers apocalyptique du « splendide blasphème » (Duhamel, 1912 : 362). Enfin, Duhamel reprend la problématique du temps concernant la place des femmes dans la littérature : "l'ardeur, le don d'image et d'émotions » (Duhamel, $1912: 362$ ) la distinguent de ses consœurs. Quelques jours plus tard, dans sa chronique sur « Les livres », Paul Souday (1912: 3) relance quelques-unes de ces idées concernant Dauguet et la poésie. Sa critique est précédée d'une réflexion générale sur la poésie et sa disparition, causée par le développement de la prose (Noailles, Régnier, Delarue-Mardrus). Il convient du manque de génie des poètes de l'époque. Quant aux contemporaines, il est catégorique : Picard est un exemple de verbiage ; la Comtesse d'Avrancourt incarne l'expression classique de la nature ; Antonine Colet exprime la « finesse de sensations » sur des thèmes comme le silence et la mort (Souday, 1912 : 3). À l'opposé, il situe l'éloquence " sauvage » et la désinvolture, autre « bacchante » émulant Dauguet. Sa bienveillance envers Dauguet pâlit face aux louanges exaltant Antonine Callet. Souday ne retient pas la thèse du panthéisme mais remarque, à l'instar de Duhamel, l'idée de la violence dans son amour pour la nature (Souday,1912 : 3). Pour lui, L'Essor victorieux n'atteint aucun sommet poétique mais incarne les « promesses » d'un recueil consacré à l'amour dans toute sa puissance, dénué de simplisme et doté de l'originale expression du « délire dionysiaque » (Souday, $1912: 3$ ). Par cette chronique, Souday replace Dauguet dans une perspective littéraire qui récupère d'une part le binarisme masculin/féminin, de l'autre la dualité poésie/roman, et qui la situe dans une école poétique féminine (Picard, Burnat-Provins, A. de Lautrec), enrichie de nouveaux noms comme Antonine Callet et la comtesse d'Avancourt.

${ }^{13}$ En 1925, dans son chapitre sur la littérature féminine, elle ne lui consacrera que deux lignes, la réduisant à une "des victimes de la mode frénétique qui sévissait au début du XXe siècle » (Charasson, $1925:$ II, 82). 
À l'approche de la guerre, les mentions à Dauguet dans la presse se font plus rares. En 1913, nous n'avons trouvé qu'un seul compte rendu. Le 27 juillet, dans un long article consacré aux " Femmes poètes », Auguste Dorchain (1913: 72-74) consacre ses dernières lignes à L'Essor victorieux (Dorchain, 1913: 73). L'intérêt de cette mention réside dans l'inclusion de la poétesse franc-comtoise dans un long commentaire sur les nouvelles œuvres des poétesses du temps. Entre janvier et juillet 1914, la présence de Marie Dauguet se réduit à une douzaine de références n'occupant que quelques lignes de plusieurs périodiques et revues. Dauguet est toutefois citée dans deux comptes rendus (Bertaut, $1914: 522$ ) (d'Yvray, 1914:178) des Nouveaux Païens de Martin-Marny (Paris, Sansot, 1914) et dans l'article d'Alphonse Séché (1914 : 66-97) sur Le Désarroi de la conscience littéraire. Selon Séché (1914 : 77), elle fait partie des meilleurs poètes et siège au Parnasse, honorée de l'aura de poétesse, auprès des grands noms de l'époque, hommes et femmes : Émile Verhaeren, Henri de Régnier, Francis Jammes, Louis Le Cardonnel, Fernand Gregh, Paul Claudel, Anna de Noailles, Hélène Picard.

\section{Conclusion}

La réception critique de Marie Dauguet dans la presse de la Belle Époque éclaire les contours d'une poétesse de notre temps et nuance l'image d'une femme de lettres que notre contemporanéité aura tardé à placer dans les rangs de la haute culture littéraire.

Marie Dauguet fit son chemin, dans un temps où rien ne laissait entendre qu'elle serait la poétesse que l'on sait, ou plutôt que l'on ne sait plus ${ }^{14}$. Un triple discours entrelace la réception critique de son œuvre : l'analyse de ses textes, les avis sur la poétesse, le débat sur les femmes et la littérature. De ce brassage d'opinions, de critiques, de lettres, de mentions, particulièrement riches pendant la Belle Époque, surgissent des éclairages pour revisiter l'écriture de cette singulière Dame du Beuchot. Contestée, acceptée ou oubliée, Dauguet apparaît comme une poétesse de la terre, tantôt érudite, tantôt sans préparation, unique en son genre ou à l'ombre des grandes autrices et des grands auteurs du moment. Originale dans sa création, elle abuse des transpositions, allant mêmes jusqu'à l'imitation. Mais les nouveaux regards ne manquent pas et Dauguet est aussi présentée comme une voyageuse, une critique d'art, et une fine observatrice des habitants de tous les paysages qu'elle dépeint, franchissant dès lors les frontières du territoire,

\footnotetext{
${ }^{14}$ À cette date il n'existe aucune édition critique des œuvres de Dauguet. Cependant les travaux de Christine Planté (1998, 2002, 2003) et de Patricia Izquierdo (2008, 2011, 2012) constituent une référence dans les études des poétesses de cette période. Quoique Broc (1911) l'omettra, une partie des anthologies de l'époque l'incorporèrent à leur choix (Casella et Gaubert, 1906 ; Walch, 1907 ; Séché, [1908] ; Normandy et Poinsot, [1909] ; Parmentier, 1909 ; Van Bever, 1909 ; Jean de Gourmont, 1910 ; Veyssié et Schuré, 1912 ; Martin-Mamy, 1914).
} 
les limites du terroir, dépassant aussi la simple vision pittoresque ou populaire ${ }^{15}$. D'ailleurs sans renoncer à sa mémoire paysanne et à ses langages populaires, elle revendique aussi l'élite intellectuelle, et littéraire. Car si Dauguet aime le naturel et la spontanéité, la vérité et la clarté, elle n'en est pas moins rationnelle, et disciplinée. Dauguet connait les classiques et les anticlassiques. L'éclectisme et le syncrétisme éthiques, esthétiques et linguistiques caractérisent la poésie de cette écrivaine hétérodoxe, libre et passionnée de vie, porteuse, comme les poétesses de cette période d'une modernité et d'un renouveau esthétique que la critique ne reconnaissait pas toujours.

Plus largement, la poésie de Dauguet, cet élan de chair et de forêt, de minéralité et de volupté, de désir et de jouissance, de travail et d'écoute, de musique et de parfums, doit être replacée dans le mouvement poétique de Sapho, des poétesses de l'école de Lyon. Mais elle sera aussi associée à celui de Marguerite Burnat-Provins, Jane Catulle-Mendès, Gérard d'Houville, Lucie Delarue-Mardrus, Jean Dominique, Anna de Noailles, Jeanne Perdriel-Vaissière, Hélène Picard, Cécile Perrin, Rosemonde Gérard, Marie Krysinska, Henri Régnier et Renée Vivien. Indépendamment de l'existence d'une école reconnue (Izquierdo, 2008 : [19]), Dauguet occupe une place de choix dans cette mouvance littéraire du temps, représentative d'un état d'esprit des femmes, liée à un féminisme naissant, contesté, accepté ou ignoré, et d'une écriture lyrique au féminin qui en hérite les controverses. Ce Parnasse féminin de la Belle Époque, placé en étau entre les écoles esthétiques finissantes du XIXe siècle et les nouvelles tendances du tournant du siècle, porteur du renouveau esthétique de la poésie moderne, cible de toutes les querelles idéologiques de ce quart de siècle de contemporanéité, est rendu visible par un discours critique foisonnant et polyphonique dont le corpus d'étude a étayé certains de ses clivages concernant la poétesse mais aussi les femmes et la littérature, leurs capacités et leurs faiblesses (intellectuelles, biologiques, sociales), leurs droits au féminin et leurs égards au masculin, la question même d'être femme et de l'écriture féminine.

Pour Dauguet, il existe une littérature féminine (Moroy, 1931 : 60) et jusqu'au bout, elle voudra que l'on publie ses œuvres. Dauguet, pour qui tout est sentiment et curiosité (1906:38), avait compris que la littérature est un acte de conscience, volontaire, voire émancipateur (Moroy, 1931:38). Son vers-librisme et ses images "malaisées » pour certains (Charasson, 1912 : 378 ) en sont une première évidence. Dauguet a fait des choix courageux que la critique n'a pas toujours saisis, que certains à l'instar de Quillard, Poinsot ou Veyssié, ont parfois consignés mais que Dauguet confirmera dans sa réponse lors d'une enquête sur la littérature féminine en 1931 : « Nous nous sommes enseignées nous-mêmes, en devenant poètes et nous naissions à la vérité avec nos premiers vers » (Moroy, $1931: 38$ ).

15 Encore aujourd'hui, Dauguet est classée parmi les poétesses de la poésie populaire (Reid, 2020 : II, 136). 


\section{RÉFÉRENCES BIBLIOGRAPHIQUES}

ABRAM, Paul (1910) : « Les Nouveaux Livres ». La Petite République, 12582, 2. Disponible sur : https://www.retronews.fr

A. de B. (1902) : " Carnet bibliographique ». La Libre Parole. La France aux Français, 3727, [4]. Disponible sur : https://www.retronews.fr

ANONYMe (1902) : " Divers ». La Patrie. Organe de la Défense Nationale, s.n., 3. Disponible sur : https://www.retronews.fr

ANONYME (1903) : "Séance du 9 février 1903 ». Bulletin de la Société des Poètes Français, 3, 2-3. Disponible sur : https://gallica.bnf.fr

ANONYME (1904a) : "Orphée change de sexe ». Les Arts de la vie, 7, 5-6. Disponible sur : https://gallica.bnf.fr

ANONYME (1904b) : «Les trois grâces ». Paris. Journal politique et littéraire du soir, s.n., [1]. Disponible sur : https://www.retronews.fr

ANONYME (1905a) : "Échos et nouvelles ». Bulletin de la Société des Poètes Français, 9, 9-10. Disponible sur : https://gallica.bnf.fr

ANONYME (1905b) : «Échos et nouvelles ». L'Opinion nationale, journal politique du matin, 814, [2]. Disponible sur : https://www.retronews.fr

AnONyme (1906) : «Choses et autres ». Le Petit Moniteur, 71, [2-3]. Disponible sur : https://www.retronews.fr

ANONYME (1907): «Bibliographie ». La Patrie. Organe de la Défense nationale, s.n., 4. Disponible sur : https://www.retronews.fr

ANONYME (1909) : «Bibliographie ». L'Aurore. Politique, Littéraire, Sociale, 4110, [2].

ANONYME (1910) : «Chronique ». Académie des sciences, belles-lettres et arts de Besançon, s.d., 182-190.

ANONYME (1911) : «Échos ». La Liberté. Journal de Paris indépendant. Politique, littéraire et financier, 16704, 2. Disponible sur : https://gallica.bnf.fr

ANSEL, Franz (1904) : «Les Poèmes ». Durendal : revue catholique d'art et de littérature, s.n., 682, 721-731. Disponible sur : https://gallica.bnf.fr

ANSEL, Franz (1905) : "Les Poèmes ». Durendal : revue catholique d'art et de littérature, s.n., 225-226. Disponible sur : https://gallica.bnf.fr

BERTAUT, Jules (1914): «Les Lettres contemporaines ». La Revue du mois, 97, 518-523. Disponible sur : https://gallica.bnf.fr

BENASSIS, Françoise (1904) : «Des livres ». La Fronde, 2107, [3]. Disponible sur : https://www.retronews.fr

BEVER, Adolphe van (1909): Les poètes du terroir du 15e siècle au $20 e$ siècle. Textes choisis accompagnés de notices biographiques, d'une bibliographie et de cartes des anciens pays de France. Paris, C. Delagrave, vol. II. Disponible sur : https://archive.org/details/lespotesduterro4beveuoft

BOQUET, Damien \& Didier LETT (2018) : «Les émotions à l'épreuve du genre ». Clio, 47, 7-22. DOI : https://doi.org/10.4000/clio.13961

Bosch, Firmin van den (1906) : «Femmes de lettres ». Durendal : revue catholique d'art et de littérature, s.n., 136-140. 
BRAHM, Alcanter de (1903) : "La poésie nouvelle. Le vers libre ». Le XIXe siècle, 12049, [1]. Disponible sur : https://gallica.bnf.fr

BROC, Hervé de (1911) : Les femmes auteurs : trois femmes poètes... Paris, Librairie Plon.

CABS, Maurice (1902) : « Le mouvement littéraire. » La République. Journal des Républicains progressistes, 815, [2]. Disponible sur: https://www.retronews.fr

CABS, Maurice (1907) : «Le livre du jour ». Gil Blas, 10058), [1]. Disponible sur : https://gallica.bnf.fr

CASELLA, Georges \& Ernest GAUBERT, (1906) : La Nouvelle Littérature (18951905). Paris, Bibliothèque Internationale d'Édition, É. Sansot et Cie.

CAZET, Jean (1909) : « Petite chronique des Lettres Françaises ». Comøedia, 519, 2. Disponible sur : https://www.retronews.fr

Chantavoine, Henri (1909) : «Variétés. Pastorales ». Journal des débats politiques et littéraires, 144, 3. Disponible sur : https://gallica.bnf.fr

Charasson, Henriette (1912) : «Les Poèmes ». Revue du Temps présent, 1, 376381.

ChARASSON, Henriette (1925) : "La littérature féminine », in Eugène Montfort, Vingt-cinq Ans de Littérature Française. Tableau de la vie littéraire de 1895 à 1920. Paris, Librairie de France, tome II, 65-98. Disponible sur : https://gallica.bnf.fr

ChARles, Étienne (1901) : «Ceux qu'on dégrade ». La Liberté. Journal de Paris, Indépendant, politique et littéraire, 13359, [1-2]. Disponible sur: https://gallica.bnf.fr

ChARLES, Étienne (1909) : « Revue des Livres. Poésie ». La Liberté, 15797, [1]. Disponible sur : https://gallica.bnf.fr

CORRARD, Jean (1910) : «Quinzaine littéraire du Gil Blas ». Gil Blas, 12194, 1-2. Disponible sur: https://gallica.bnf.fr

DAUGUET, Marie (1902a) : «À la primevère ». Mercure de France, 146, 410-412. Disponible sur : https://gallica.bnf.fr

DAUGUET, Marie (1902b) : À travers le voile. Novembre 1899-novembre 1901. Paris Librairie Léon Vanier, éditeur.

DAuguet, Marie (1904a) : «Une lettre de $\mathrm{M}^{\text {me }}$ Marie Dauguet ». in Pierrre Quillard, Mercure de France, 180, 721-723. Disponible sur: https://gallica.bnf.fr

Dauguet, Marie (1904b) : Par l'Amour. Poèmes. Paris, Société Mercure de France. Disponible sur : https://gallica.bnf.fr

DAuguet, Marie (1906) : « Marie Dauguet ». Revue littéraire de Paris et de Champagne, 40, 228-231. Disponible sur : https://gallica.bnf.fr

DAUGUET, Marie (1907) : Clartés, notes et pochades. Italie, printemps et été. Paris, Librairie E. Sansot.

DAuguet, Marie (1908a) : Les Pastorales. Poèmes. Paris, Librairie E. Sansot.

DAuguet, Marie ([1908b]) : « [Lettre de Marie Dauguet à A. Séché] », in Alphonse Séché, Les Muses françaises. Anthologie des femmes-poètes (XX $X^{e}$ siècle). 
Morceaux choisis. Paris, Louis Michaud, tome II, 59-73. Disponible sur : https://archive.org

Dauguet, Marie (1909): "Futurisme ». Poesia, 3-4-5-6, 71. Disponible sur : https://archive.org

DAuguet, Marie (1911) : «En vacances », in Robert Veyssié, « Le carnet littéraire ». Gil Blas, 12597, [3]. Disponible sur : https://gallica.bnf.fr

DAuguet, Marie (1931) : «La poésie de $\mathrm{M}^{\mathrm{me}}$ Marie Dauguet [...] », in Élie Moroy, La Littérature Féminine définie par les Femmes Écrivains. Enquête sur les lettres de ce temps. Genève, Semaine de Genève, 37-38.

Dauguet, Marie (1938) : Passion. Paris, Albert Messein, éditeur. Disponible sur : https://gallica.bnf.fr

DESCHAMPS, Gaston (1904) : « La vie littéraire ». Le Temps, 15722, [2]. Disponible sur : https://gallica.bnf.fr

DorChain, Auguste (1913) : « Revue des Livres. La Poésie. Les femmes poètes ». Les Annales politiques et littéraires. Revue Universelle paraissant le Dimanche, 1570, 72-74. Disponible sur : https://gallica.bnf.fr

DORGELÈS, Roland (1925) : « Le cadastre littéraire ou une heure chez M. Barrés ». La Vie parisienne » : mours élégantes, choses du jour, fantaisies, voyages, théâtres, musique, modes, 21, 367-371. Disponible sur: https://gallica.bnf.fr

DoRNIS, Jean (1911) : « La Natures Inspiratrice ». Figaro : journal non politique, 203, [1]. Disponible sur : https://gallica.bnf.fr

DU FreSnOIS, André (1907) : « M Me Marie Dauguet ». La Phalange, 1041-1043.

DUHAMEL, Georges (1912) : «Les poèmes ». Mercure de France, 354, 361-362. Disponible sur : https://gallica.bnf.fr

EcK, Héléne \& Claire BLANDIN [éds] (2010) : La Vie des femmes. La presse féminine au XIXème et XXème siècles. Paris, Panthéon Assas.

ERNEST-CHARLES, Jean (1905) : «Récompenses Académiques ». Gil Blas, 9354, [1]. Disponible sur : https://gallica.bnf.fr

ERNEST-CHARLES, Jean (1909) : «La vie littéraire ». La Grande Revue, 54, 789801.

FAGUET, Émile (1902) : "Poètes ». La Revue latine. Journal de littérature comparée : France, Espagne, Italie, Belgique, Suisse française, Roumanie, Canada, etc., 9, 528-534. Disponible sur : https://gallica.bnf.fr

FAGUET, Émile (1908) : «Poètes ». La Revue latine : journal de littérature comparée : France, Espagne, Italie, Belgique, Suisse française, Roumanie, Canada, etc. 2, 65-103. Disponible sur : https://gallica.bnf.fr

FAGUET, Émile (1910) : Le Féminisme. Paris, Société Française d'Imprimerie et de Librairie.

FARALICQ, René (1902) : "Chronique des livres ». La Revue hebdomadaire : romans, histoire, voyages, I, 342-345. Disponible sur : https://gallica.bnf.fr

FEYEL, Gille (2007) : La presse en France des origines à 1944 : Histoire politique et matérielle. Paris, Ellipses. 
FOLEY, Charles (1904) : «La Semaine littéraire ». L'Écho de Paris. Journal politique et littéraire du matin, 7370, 2. Disponible sur: https://www.retronews.fr

GHÉON, Louis (1904) : «Chroniques du mois ». L'Hermitage. Revue mensuelle de littérature, 8, 309. Disponible sur : https://gallica.bnf.fr

GoffIN, Arnold (1907) : «Clartés, Notes et Pochades, par M ${ }^{\text {me }}$ Marie Dauguet ». Durendal : revue catholique d'art et de littérature, s.n., 412. Disponible sur : https://gallica.bnf.fr

Gourmont, Rémy de (1904) : «Un poète de la nature ». Mercure de France, 173, 390-397. Disponible sur : https://gallica.bnf.fr

Gourmont, Jean de (1910) : Les Muses d'aujourd'hui. Paris, Mercure de France. Disponible sur : https://archive.org

HARLOR (1902) : «À travers l'art». La Fronde, 1760, 2. Disponible sur : https://www.retronews.fr

IZQUIERDO, Patricia (2008) : "L'importance de V. Hugo chez certaines poétesses de la belle époque ». Communication du Groupe Hugo du 21 juillet 2008. Disponible sur: http://groupugo.div.jussieu.fr/Groupugo/o8-06-21Izquierdo.htm

IZQUIERDO, Patricia (2009): Devenir poétesse à la Belle Époque (1900-1914). Étude littéraire, historique et sociologique. Paris, L'Harmattan.

IZQUIERDO, Patricia (2012) : « L’influence de Francis Jammes sur quatre poétesses contemporaines ». Cahiers Francis Jammes, 1, 109-119. Disponible sur : https://gallica.bnf.fr

KAHN, Gustave (1905) : «Au jour le jour. L'Académie des poètes ». Le Siècle, 25214, [1]. Disponible sur : https://www.retronews.fr

KAHN, Gustave (1908) : «L'anthologie de Gil Blas ». Gil Blas, 10403, [2]. Disponible sur: https://gallica.bnf.fr

LE CARDONNEL, Georges \& Charles VELAY (1905) : La littérature contemporaine. Paris, Mercure de France.

LE GofFIC, Charles (1909) : « Nos poètes ». La Revue hebdomadaire et son supplément illustré, 2, 247-268. Disponible sur : https://gallica.bnf.fr

LE GOFFIC, Charles ([1925]) : La littérature régionaliste: conférence prononcée le 20 février 1925 au Cercle de la Libraire dans le cadre des Causeries françaises. Paris, Impr. J. Dumoulin, 1-16.

LE MASQue DE VerRe (1911) : «Échos ». Comodia, 1508, [1]. Disponible sur : https://gallica.bnf.fr

LE WATTMAN (1911) : « Nos échos. On dit que... ». L'Intransigeant et le Journal de Paris, 11448, [2].

LES MÉRIDIENS (1925) : «Révision du cadastre ». Paris-midi : seul journal quotidien paraissant à midi, 2, 2. Disponible sur : https://gallica.bnf.fr

LIEBRECHT, Henri (1905) : «Chronique littéraire ». Le Thyrse. Revue d'Art mensuelle, s.n., 253-254. Disponible sur : https://archive.org

MARION, Paul (1904) : «Les livres. ». La République française. Journal des républicains libéraux et progressistes, 11870, 2-3. Disponible sur: https://www.retronews.fr 
MARTIN-MARNY, Eugène (1914) : Les Nouveaux Païens. Paris, E. Sansot.

Martineau, Henri (1910) : «Les Chroniques. Les Poèmes ». Le Divan, 7, 237-245. Disponible sur : https://gallica.bnf.fr

MartineaU, Henri (1911) : « Les Chroniques. Les Poèmes ». Le Divan, 17, 315-316. Disponible sur : https://gallica.bnf.fr

MERELLO, Ida (2010) : "L'héritage symboliste au tournant du siècle : la technique $\mathrm{du}$ vers libre». Studi Francesi, 160, 13-23. DOI : https://doi.org/10.4000/studifrancesi.7098

MERriLl, Stuart (1903) : "Critique des Poèmes ». La plume littéraire, artistique, politique et sociale, 1, 29-44. Disponible sur : https://gallica.bnf.fr

MirTEL, Héra (1911) : "Variétés. Dame et solduriers ». Le Soleil, 326, 3.

MOLLIER, Jean-Yves (1997) : « La naissance de la culture médiatique à la BelleÉpoque : mise en place des structures de diffusion de masse ». Études littéraires, 1, 15-26. DOI : https://doi.org/10.7202/501184ar

MOROY, Élie (1931) : La Littérature Féminine définie par les Femmes Écrivains. Enquête sur les lettres de ce temps. Genève, Semaine de Genève.

Moulin, Jeanine (1960) : « Pour le centenaire de la naissance de Marie Dauguet ». Les Annales, 114, 39-40.

Moulin, Jeanine (1963) : La poésie féminine. De Marie de France à Marie Noël. Paris, Seghers.

NER, Henry (1897) : «Le massacre des amazones. Étude critique sur les bas-bleus d'aujourd'hui ». La Plume, Genève, Slatkine Reprints (1968), 693-694, 718-720, 792, 805-807. Disponible sur : https://gallica.bnf.fr

NORMANDY, Georges \& M[affeo]-C[harles] POINSOT ([1909] : Les poètes sociaux : anthologie de poésies sociales. Paris, Louis Michaud, éditeur.

Nотномв, Pierre (1909) : « Marie Dauguet ».Durendal : revue catholique d'art et de littérature, s.n., 446-450. Disponible sur : https://gallica.bnf.fr

OTT, Jean (1907) : « Le mois poétique ». La Revue septentrionale : organe des Rosati et des sociétés savantes, artistiques et littéraires du Nord de la France, 4, 103-108. Disponible sur : https://gallica.bnf.fr

PALMER, Michael (2016) : "L’âge d'or de la presse ». Le Temps des médias, 27, 2, 97-110. DOI : 10.3917/tdm.027.0097

PARMEnTIER, Florian [éd.] : Toutes les lyres. Anthologie des poètes contemporains. Paris, Gastein-Serge, 1909.

PARVILLE, Henri de (1901) : «Revue des sciences ». Journal des débats politiques et littéraires, 58, 1-2. Disponible sur : https://www.retronews.fr

PESCH, Édouard (1902) : «La Revue des Livres. Librairie Léon Vanier ». L'Autorité, 253, 3. Disponible sur : https://www.retronews.fr

PIP (1902) : « Carnet de Paris ». La Nouvelle revue, XVII, 418-423. Disponible sur : https://gallica.bnf.fr

PIP (1905) : "Carnet de Paris ». La Nouvelle revue, XXIV, 414-418. Disponible sur : https://gallica.bnf.fr

PlanTÉ, Christine (1998) : Femmes poètes du XIXe siècle: une anthologie. Lyon, Presses universitaires de Lyon. 
PlanTÉ, Christine [éd.] (2002) : Masculin / Féminin dans la poésie et les poétiques $d u \quad X I X^{e}$ siècle. Lyon, Presses universitaires de Lyon. DOI : https://doi.org/10.4000/books.pul.6258.

PlanTÉ, Christine (2003) : « La place des femmes dans l'histoire littéraire : annexe, ou point de départ d'une relecture critique ? ». Revue d'histoire littéraire de la France, 3, 655-668.

PoInsot, M[affeo]-C[harles] (1903) : "Conception moderne de l'art ». La Pensée. Revue de Littérature d'Art et de Sociologie, 61-63, 3-8. Disponible sur : https://www.retronews.fr

PoInsot, M[affeo]-C[harles] (1911) : Esthétique régionaliste. Paris, E. Figuière.

PoINSOT, M[affeo]-C[harles] (1923) : L'art littéraire. Paris, La Maison française d'art et d'édition.

PrAVIEL, Armand (1909). « François Coppée ». Revue des Pyrénées et de la France méridionale : organe de l'Association pyrénéenne et de l'Union des sociétés savantes du Midi. 21, 551-566.

QUILLARD, Pierre (1902) : « Les poèmes. «À travers le voile ». Mercure de France, 738-739. Disponible sur : https://gallica.bnf.fr

QUILlaRD, Pierre (1904) : «Une lettre de $\mathrm{M}^{\text {me }}$ Marie Dauguet ». Mercure de France, 180, 721-723. Disponible sur : https://gallica.bnf.fr

QUILlard, Pierre (1909) : «Les Poèmes ». Mercure de France : série moderne, 282, 306-311. Disponible sur : https://gallica.bnf.fr

REID, Martine [éd.] (2020) : Femmes et littérature. Une histoire culturelle. II, Paris, Folio /Inédit essais.

RICHARD-MOUNET, Louis (1912) : "Critiques et notes. Les poèmes ». Vers et prose: recueil trimestriel de littérature, 31, 137-138. Disponible sur: https://gallica.bnf.fr

RioToR, Léon (1903) : « Le Rappel artistique et littéraire ». Le XIXe siècle, 12025, [1]. Disponible sur : https://gallica.bnf.fr

S. (1904) : «Variétés. Poésie ». Journal des Débats Politiques et Littéraires, 242, 3. Disponible sur : https://gallica.bnf.fr

SAdOUL, Charles (1909) : «Les livres ». Le Pays lorrain : revue régionale bi-mensuelle illustrée, A6, 782. Disponible sur : https://gallica.bnf.fr

SAINT-JEAN, Pierre de (1907) : «Bibliographie traditionniste ». Revue du traditionnisme français et étranger : avec la bibliographie des provinces de France, s.n., 179. Disponible sur : https://gallica.bnf.fr

SAINT-JEAN, Pierre de (1909) : "Bibliographie ». Revue du traditionnisme français et étranger : avec la bibliographie des provinces de France, 1, 53-54. Disponible sur : https://gallica.bnf.fr

SAINT-PoINT, Valentine (1909): "Chronique littéraire. La femme dans les lettres ». Le Petit Bourguignon, 10278, 4. https://www.retronews.fr

SCHLumberger, Jean (1909) : «Les Pastorales par Mme Marie Dauguet ». La Nouvelle Revue Française, 1, 94-96, 110.

SÉCHÉ, Alphonse ([1908]) : Les Muses françaises. Anthologie des femmes-poètes (XX $X^{e}$ siècle). Morceaux choisis. Tome II, Paris, Louis Michaud. Disponible sur : https://archive.org 
SÉCHÉ, Alphonse ([1914]) : « Le désarroi de la conscience littéraire ». La Revue du mois, 97, 66-87. Disponible sur : https://gallica.bnf.fr

SoudAY, Paul (1912) : «Les livres. Les poètes ». Le Temps, 18530, 3. Disponible sur : https://gallica.bnf.fr

THIESSE, Anne-Marie (1983) : « La littérature régionaliste : Préhistoire de l'ethnologie française ? ». Bulletin de l'Association française des anthropologues, 12-13, 36-45. DOI : https://doi.org/10.3406/jda.1983.1101

TrESSERRE, François (1909) : «L'Enclos des Poètes, Églogues modernes ». L'Âme latine. Revue de Littérature, d'Art et de Sociologie, 11, 33-38.

VALDAGNe, Pierre (1910) : "Revue des Livres Nouveaux ». Touche à tout. Magazine des Magazines, 10, 477. Disponible sur : https://gallica.bnf.fr

VeYsSiÉ, Robert (1911a) : «Le carnet littéraire ». Gil Blas, 12553, [3]. Disponible sur : https://gallica.bnf.fr

VEYssié, Robert (1911b) : «Le carnet littéraire ». Gil Blas, 12578, [3]. Disponible sur : https://gallica.bnf.fr

VeYsSiÉ, Robert (1911c) : «Le carnet littéraire ». Gil Blas, 12579, [3]. Disponible sur : https://gallica.bnf.fr

VEYSSIÉ, Robert (1911d) : « Le carnet littéraire ». Gil Blas, 12597, [3]. Disponible sur : https://gallica.bnf.fr

VeYsSiÉ, Robert (1911e) : «Le carnet littéraire ». Gil Blas, 12653, [3]. Disponible sur : https://gallica.bnf.fr

VEYSSIÉ, Robert (1911f) : «Les Lettres - La semaine poétique ». Gil Blas, 12699, [2]. Disponible sur : https://gallica.bnf.fr

VEYSSIÉ, Robert (1912) : Poètes français. Première anthologie de la Renaissance contemporaine. Précédée des Quinzaines poétiques. Paris, La Renaissance contemporaine.

WALCH, Gérard (1907) : Anthologie des poètes français contemporains. Paris, Ch. Delagrave, éditeur. 3 tomes.

YVRAY, Jehan de (1914) : "Les romans et les livres ». Le Parthénon : revue politique et littéraire, indépendante, 3, 178-180. Disponible sur : https://gallica.bnf.fr 